\title{
Overcoming Stigma-Threat Motivated Non- DisClOSURE OF RAPE VICTIMS THROUGH RATIONAL EMOTIVE BEHAVIOUR THERAPY (REBT)
}

\author{
Idoko Boniface Idoko, Igbo Happiness, Yakubu, Meremu. \\ Principal, Emmanuel Secondary School Ugbokolo, Benue State Nigeria. \\ Department of Educational Foundations, Faculty of Education, Benue State University \\ Makurdi. \\ School Counsellor, UBE Girls’ Juniour Secondary School, Makurdi, Benue State Nigeria.
}

\begin{abstract}
The scourge of rape in our contemporary society seems to have a smooth sail on the opportunity of nondisclosure of rape cases by the victims due to stigma threat. Rape is an act of forcefully having sex with someone against the will of such a person. This cannot be encouraged in any civil society. The social stigma associated with rape across the globe forces the victims to conceal rape assaults in order to save themselves from shame and public embarrassment. . Counseling as a helping profession is capable of helping rape victims who suffer in silence due to stigma threat to manage and overcome such difficulties through behaviour modification techniques. This paper advocates the use of Rational Emotive Behavior Therapy (REBT), to eliminate stigma threat nondisclosure. It recommends that Counselors should help rape victims to embrace life more positively through REBT and other behaviour modification therapies. Counsellors through individual and group counselling should employ the use of REBT to discard the irrational thoughts that promotes stigma threats that motivate nondisclosure in the victims.
\end{abstract}

\section{KEYWORDS:}

Rape, Stigma, Threat, Nondisclosure, Victims, Counseling, Counselors, Rational, Irrational, Rational Emotive Behavior Therapy (REBT)

\section{INTRODUCTION}

All through the track of time women have always been professed as the fragile vessel, and so have been subdued and oppressed by culture in most societies. The culture is defined by inequity and the subjugation of the female folk. Gender-based violence, including rape, domestic violence and other sexual abuses, have assumed serious proportions globally. In the world at large commonness of rape are fast assuming a threatening dimension that requires urgent intercession. Rape, like other forms of violence against women, is a violation on women's rights, privacy, self-preservation and dignity. Available data in the media reveal that rape issue has become a serious social problem of epidemic percentage and no longer an isolated criminal act affecting just a few women in the society (Eze 2013, Renolds 2018, Hendler 2019).

In recent times the commonness of rape has increased at a disturbing rate, this may be attributed to the fact of nondisclosure which is mostly motivated by stigma-threat. Negative social reactions in

DOI : $10.5121 /$ ije. 2019.7301 
response to disclosure by families, friends, partners, and the society at large instill fear into rape victims. And because of perceived stigma, rape victims suffer in silence. For Kennedy and Prock (2012), Stigma and stigmatization play a critical role in shaping rape victims' thoughts, feelings, and behaviours as they recover; their risk of revictimization; and their help-seeking and attainment process. If there is little or no policy or law that helps protect rape victims when rape cases are brought to the public domain and they are instead blamed, stigmatized and humiliated by the public, nondisclosure of rape incidence by rape victims will abound. Rape is not a delightful sight to behold. It is so demoralizing for the victims, even when the assaulters are persecuted in rare cases. There is therefore an urgent need for this menace to be tamed.

\section{CONCEPT OF RAPE}

Rape is a common word in our modern society and so has the act become common. People get into sexual contact with others without the consent of the victims. Rapists invade the privacy of their victims and infringe on their rights as human beings. Rape is defined for research and policy as penetrative, nonconsensual sex that is enacted with some degree of force (physical or verbal) or threat of violence that may be perpetrated by a stranger, family member, significant other, or other associates (Wood, Lambert, \& Jewkes, 2008). Agbo (2019), simply defined rape as the crime of forcefully having sexual relationship with somebody against the person's wish or consent. Rape is the act of forcefully going against the consent of a person by having sex with such a person. It is a sexual penetration by one person against another person without the consent of the victim. Rape denies women of their self-preservation, it is the invasion of their privacy, this is not for human beings and so it is a condemnable act. Getting raped can cause in an immense level of trauma for the victims. Gluck (2012), maintained that rape victims endure the immediate physical and mental trauma of the actual event as well as many ongoing psychological challenges. Rape has grave health consequences for the victims, these may include: unwanted pregnancy, abortion, which can result in death, Sexually Transmitted Infections (STIs) including HIV. According to Peters and Olowa (2010), rape has serious reverberation effects which include physical and psychological trauma, gynecological problems such as sex trauma, urinary tract infection and sexually transmitted infections. As such, rape should be controlled by the state with all seriousness. However, what obtains in many countries is that the society and the legal system make it very difficult for rape victims to obtain justice. Often victims are stigmatized and are presented as public disgrace to their

families and may have serious implications for future relationships such as marriage. As a result of this, rape victims and their families are silent about their tribulation, thereby helping the rapist to escape from being punished.

\section{CONCEPT OF STIGMA}

Stigma has to do with negative views held about someone or a mark of shame or disgrace associated with particular circumstances. Dudley (2000), defined stigma as stereotypes or negative views attributed to a person or groups of people when their characteristics or behaviours are viewed as different from or inferior to societal norms. Phelan (2001) sees stigma along more sociological lines as a way of naming a situation in which "elements of labeling, stereotyping, separation are clearly distinguishable. Stigma, according to Kennedy and Prock (2016), refers to the negative connotations, example, badness, shame, and guilt, that are communicated to the victim around the experiences and that then become incorporated into the victim's self-image. These negative meanings are communicated in many ways. They can come directly from the abuser, who may 
blame the victim for the activity, demean the victim, or furtively convey a sense of shame about the behaviour.

Stigma could be viewed in various categories or types. The World Vision UK's research on the impact of stigma faced by survivors of sexual violence in conflict zones (2016), gave the following as different types of stigma. (i) Self-imposed Stigma: This is the guilt and shames that survivors place upon themselves. According to the report, in 2011, for example, research by the Harvard Humanitarian Initiative revealed that one in ten females in the DRC (where civil wars and unrest have raged since1996) believed that their being raped was a punishment from God. (ii) Familial Stigma: Some societies believe it is difficult for rape to lead to conception. Often, women and girls who conceive as a result of an attack are not believed by their families. Juvenile mothers of children born through rape lose their 'child status' and the parental support that goes with it. The husbands of female survivors face pressure from friends and family to leave their wives, whilst children who saw their mother being raped may later blame her for not stopping the attack. Unfortunately, some families even try to ostracize a survivor to avoid the burden of post-trauma and costly therapies or drugs. (iii) Community Stigma: This form of stigma is connected to deeprooted societal and cultural beliefs. It mainly relates to the victim-blaming of female survivors; 'she was dressed inappropriately' or is guilty of marital infidelity. In communities where sex before marriage is reviled, female victims of rape are seen as no longer marriageable and pre-existing engagements are broken off. Mothers of children born of rape may be forced to marry any man willing to accept them, leaving them susceptible to even further abuse. (iv)Stigma by association: The fear of contracting HIV/AIDS or other sexually transmitted infections (STIs) from survivors is another reason why people shun them and reassurances that they pose no threat are largely ignored. Girls in one community explained: "Some teachers will say to students, "you see that girl... she has this problem (she has been raped) ... you should not talk to her or you will get sick." Stigma generally shows forth in various forms such as: victim-blaming, spousal abandonment, isolation, physical abuse, exclusion from public life and economic security.

\section{RAPE AND STIGMATIZATION}

Stigmatization following rape is a common and disturbing occurrence that may impact a woman's recovery long after the actual assault. The social stigma associated with rape across the globe forces female victims to conceal rape assaults in order to save themselves from shame and public embarrassment. Even parents of the raped often find it difficult to come out openly to report such cases. When a woman is raped and is brought to public awareness, she and her family are "detested" due to the shame associated with rape. Muoghalu (2012), opines that the hegemonic patriarchal values and practices make it difficult for women who are raped to obtain justice and so rape victims suffer in silence due to the stigma and humiliation attached to public acknowledgement of rape. Another reason for not taking bold step in reporting such cases, according to Chiazor, Ozoya, Udume \& Egharevba (2016), could be for the victim's family to conserve the ever existing amiable relationship with the parents of the perpetrator of the heinous crime. This situation encourages other intenders to go into raping since people who indulge in it go scot-free. 


\section{Stigma Threat-Motivated Non-Disclosure}

Some studies have empirically investigated non-disclosure that is motivated by stigma threat and its implications for negative recovery following sexual assault (Ahrens, 2006; Gibson \& Leitenberg, 2001). Ahrens (2006), conducted a qualitative narrative analysis of interview with eight rape survivors and found that negative social reactions from formal and informal support providers led women to cease disclosing their experiences. Ahrens concluded that fears of being blamed, doubted, and treated insensitively (stigma threat) were pervasive and suggested that future research examine the impact of stigma threat-motivated "silence" on survivors' recovery.

Studies have yielded evidence that stigma threat motivated non-disclosure is related to greater psychological vulnerability following sexual assault and, perhaps, a maladaptive recovery course. Miller, Erika, Amacker, Backstrom \& Gidycz (2011), revealed that stigma-threat prospectively predicted sexual revictimization. Stigma threat-motivated non-disclosure in sexual assault victims was related to poorer adjustment. Moreover, Gibson and Leitenberg (2001) found in a sample of undergraduate sexual assault survivors that stigma threat, namely feared negative reactions from

others for example, blame, disrespect, shame and embarrassment, mediated the relationship between childhood sexual victimization and disengagement coping following an adult victimization. Perceived stigma predicted $22 \%$ of the variance in disengagement coping following the adult victimization.

Many women who have been raped suffer in silence without reporting the incident to law enforcement agencies. Onyejekwe (2008) maintained that a culture of silence aggravates this problem partly from humiliation and intimidation of victims by the police as well as the embarrassment of public acknowledgement. In addition to this, being ostracized by those who consider rape as bringing dishonour to the woman's family and community worsens the situation. Onyejekwe concludes that this culture of silence reinforces the stigma already attached to the victim rather than to the perpetrator, as the dominant perception is that women have provoked the abuser to attack. As such, victims are often unwilling to testify about their experiences. Apart from the physical aspect, some of the rape victims suffer mental health problems and trauma and other health hazards such as sexually transmitted infections including HIV/AIDS.

\section{Overcoming Stigma-Threat Motivated Non-Discloure Of RAPE VICTIMS THROUGH RATIONAL EMOTIVE BEHAVIOUR THERAPY (REBT)}

Stigma threat stands out as a major motivation for non-disclosure of rape in our contemporary society. Rape victims are often left to nurse their wounds in silence basically because of their fear of what the society will say about them. Counselling as a helping profession is capable of helping rape victims who suffer in silence due to stigma threat to manage and overcome such difficulties through behaviour modification techniques, such as the use of Rational Emotive Behaviour Therapy (REBT).

REBT came through Albert Ellis (1973), who believed that most people's thoughts about themselves are irrational, and they are not aware of this. Ellis holds that it is these thoughts that lead people to suffer negative emotions and engage in self-destructive behaviours. This implies that a person's irrational belief systems accounts for the person's problems most of the times. Doing away with the irrational thoughts then, and replacing them with rational ones, helps the individual to be able to overcome his difficulties, accept one's self better and have more fulfillments in life. 
Stigma threat leads to non-disclosure by rape victims because of fear of rejection, fear of being misunderstood, fear of being looked down on, lack of confidence, and low self-esteem. These build up illogical thoughts. According to Ellis, these illogical thoughts can be eliminated by the introduction of logical thoughts.

A rape victim may be tempted to conceal it because of irrational thoughts like:

i. Everybody will know about it.

ii. Everybody will laugh at me.

iii. Nobody will want to marry me again.

iv. My future is completely destroyed.

v. Nobody will respect me again.

vi. Nobody will believe my own side of the story.

vii. I am helpless, there's nothing I can do.

These irrational thoughts are capable of preventing the victim from ever disclosing her conditions. To help such a victim, the counsellor could replace these irrational thoughts with :

i. Everybody will not know about it simply by me reporting to the right persons.

ii. Certainly not everybody will laugh at me.

iii. Some persons will still want to marry me.

iv. My future is not finished.

v. My future is more than this single incident of rape.

vi. Many people of course, will still respect me .

vii. Many will believe my side of the story.

viii. I am not helpless. The law is on my side.

It is therefore important that counsellors should help rape victims embrace life more positively through REBT and other behaviour modification therapies. Counsellors through individual and group counselling should employ the use of REBT to discard the irrational thoughts that promotes stigma threats that motivate non-disclosure in the girl-child.

\section{Conclusion}

The persistence of rape menace in modern society no doubt has non-disclosure by the rape victims as a contributing factor. This should be a thing of grave concern to all in the society, as it poses great danger to the entire society. Counsellors as professionals in helping people to resolve their problems are very vital instruments that can be used to curb the menace. The use of REBT and other therapies will in no small measures help not only the rape victims, but the entire society to appreciate the need to open up in such circumstances. This will in turn reduce the ugly trend of rape that is becoming a major threat to our society. 


\section{RECOMMENDATIONS}

Based on the above discuss, the following recommendations are made:

1. In addition to REBT, counsellors should encourage parents to build strong, healthy and open relationship with their female children to enable them feel free enough to disclose cases of sexual assaults and rape.

2. Counsellors in schools should give attention to educating the girl-child on the dangers of rape and the need to be open in times of assault.

3. Counsellors should take advantage of the guidance services to enlighten the general public on the negative effects of non-disclosure of rape cases. Information services shall be a useful tool in fighting stigma threat non-disclosure of rape by the girl-child victim.

4. Counsellors should strive to reach out to parents, guardians, teachers, community leaders, religious leaders and other care givers to educate them on the dangers of non-disclosure of rape cases on the girl-child victim, the family and the society at large.

5. Counsellors can achieve this through effective public enlightenment campaigns. These can be done during seminars and workshops., Public enlightenment can also be done by producing pamphlets and other publications as well as making radio and television jingles.

\section{REFERENCES}

[1] Agbo, M.C.(2019). Child Rape in Nigeria, Implications on the Education of the Child. Retrieved 4th August,2019 from http://dx.doi,org/1022158/ct.v2n1np13

[2] Ahrens, C. E. (2006). Being silenced: the impact of negative social reactions on the disclosure of rape. American Journal of Community Psychology, 38, 263-274.

[3] Chiazor, I.A., Ozoya, M.I., Udume, M. \& Egharevba, M.E. (2016). Taming the rape scourge in Nigeria: issues and actions. Gender \& Behaviour, 14(3),7764-7785.

[4] Dudely, J.R. (2000). Confronting Stigma within the Services System Social Work. Retrieved 4th August, 2019 from https://www.ncbi.nih.gov

[5] Eze, U.O. (2013). Prevention of sexual assault in Nigeria. Annals of Ibadan Postgraduate Medicine.11(2),65-70.

[6] Gibson, L. E. and Leitenberg, H. (2001). The impact of child sexual abuse and stigma on methods of coping with sexual assault among undergraduate women. Child Abuse and Neglect 25:1343-61.

[7] Gluck, S. (2012). Getting Raped: The Stigma of Being a Raped Victim, HealthyPlace. Retrieved 2nd August, 2019 from http://www.healthyplace.com/abuse/rape/getting-raped-the-stigma-of-being-a-rapedvictim

[8] Hendler, M. (2019). The Global Rape Epidemic. Retrieved 4th August, 2019 from http://medium.com/womens-march-global/equality-now-report-the-global-rape-epidemic-6ea57289a127

[9] Kennedy, A.C. and Prock, K.A. (2016). Assault and sexual revictimization: a prospective analysis. Psychology of Women Quarterly, 35, 119-128 
[10] Miller, A. K., Erika J. C., Amanda, M. A., Tamika, L. B. and Gidycz. C.A. ( 2011). Stigma-threat motivated nondisclosure of sexual assault and sexual revictimization: a prospective analysis." Psychology of Women Quarterly. 35:119-28.

[11] Muoghalu, C.O. (2012). Rape and Women's Sexual Health in Nigeria: The Stark Realities of Being Female in a Patriarchal World. The African Anthropologist, (19) 1-2.

[12] Onyejekwe, C.J. (2008). Nigeria: the dominance of rape. Journal of international women's Studies, $10: 1-17$

[13] Phelan, J.C. (2001). Conceptualizing stigma. Annual Review of Sociology 27:363-85.

[14] Peter, T.O. and Olowa, O.W. (2010). Causes and influence of rape among middle age and young adult in Lagos state Nigeria. Research Journals of Biological Sciences,5:670-677.

[15] Renold, E. (2018). 'Feel what I feel': making da(r)ta with teen girls for creative activisms on how sexual violence matters. Journal of Gender Studies. 27:37-55

[16] Wood, K., Lambert, H. and Jewkes, R. (2008). Injuries are beyond love: physical violence in young South Africans' sexual relationships. Journal of Medical Anthropology, 27:43-60. 